\title{
Doses to biota in the vicinity of Sellafield, UK, and radiological protection of the environment
}

\author{
D. Jackson, D. Copplestone ${ }^{1}$ and M. Johnson ${ }^{2}$
}

\author{
Westlakes Research Institute, International Research and Graduate Centre, \\ Westlakes Science and Technology Park, Moor Row, Cumbria CA24 3JY, U.K. \\ ${ }^{1}$ Environmental Research and Consultancy, University of Liverpool, Vanguard Way, \\ Birkenhead, Wirral CH42 9HX, U.K. \\ ${ }^{2}$ Jones Building, School of Biological Sciences, University of Liverpool, Liverpool L69 3BX, U.K.
}

\begin{abstract}
Concentrations of ${ }^{134} \mathrm{Cs},{ }^{137} \mathrm{Cs},{ }^{238} \mathrm{Pu},{ }^{239+240} \mathrm{Pu}$ and ${ }^{241} \mathrm{Am}$ have been assessed for biota in three seminatural ecosystems (coniferous woodland, salt marsh and sand dunes) in the vicinity of the nuclear reprocessing plant at Sellafield, Cumbria, UK. Using dosimetric models developed for this purpose, estimates of absorbed dose rates $\left(\mathrm{mGy} \mathrm{d}^{-1}\right)$ have been calculated for small mammal and invertebrate populations selected as indicator species in each of the study sites. The derived doses are generally three orders of magnitude lower than at which no observable effects in biota are thought to occur. However, the dose threshold assumed $\left(1 \mathrm{mGy} \mathrm{d} \mathrm{d}^{-1}\right)$ requires further substantiation across a broad range of taxa. There is evidence that the postulated dose threshold may be overrestrictive, although this may be qualified by the life cycle stage of the organism (neonate, juvenile, metamorphic etc) and other factors. In particular, it is recognised that absorbed dose may not provide an adequate indicator of biological effectiveness. A tentative proposal is made for the determination of 'weighted absorbed doses' which takes some account of potential differences in radiotoxicity. The use of bioindicators, critical groups, sensitive and reference organisms for dose assessment is explored, and consideration is given to the application of genetic biomarker techniques as a measure of biological damage.
\end{abstract}

\section{INTRODUCTION}

Environmental radiological protection currently involves primarily the assessment and control of radiation exposure to human populations resulting from the authorised disposal of radioactive wastes into the environment or the accidental release of radionuclides from a nuclear facility. This approach is based on statements made by the International Commission on Radiological Protection [e.g. 1] to the effect that, if man is adequately protected from ionising radiation, then so are all other species. However, an exclusive focus on human protection is inconsistent with the protection approach applied to nonradioactive discharges [2]. Whilst the ICRP philosophy may well represent a reasonable approach, given the very low limits on permissible exposure to man, there is little direct evidence to support this position [3,4] and much of the emphasis on environmental protection for non-radioactive discharges is based on the premise that to protect the environment is also to protect human populations [5].

Increasing public and political pressure to introduce statements relating to environmental protection is evident in international conventions, such as OSPAR, and in national authorisations to discharge radioactive waste. There is also increasing recognition that the environment should be protected from the combined impact of radioactive and non-radioactive substances.

This paper describes the doses estimated for indicator wildlife species inhabiting three semi-natural ecosystems subject to inputs of anthropogenic radioactivity from routine authorised discharges from the British Nuclear Fuels plc (BNFL) nuclear fuel reprocessing plant at Sellafield, Cumbria, UK, and other sources (e.g. weapons test fallout and the Chernobyl nuclear reactor accident). The estimated doses are compared to a guideline threshold value, aspects of which are discussed.

\section{FIELD SITES}

The field sites described in this study are all within $15 \mathrm{~km}$ of BNFL Sellafield. Lady Wood is a planted monoculture of sitka spruce (Picea sitchensis) surrounded by agricultural land. It has been largely unmanaged for over 40 years and is densely populated with a uniform canopy structure under which few grass and herbaceous species grow. The bulk of the anthropogenic radioactivity present at this site is is frived from the routine aerial discharges from the Sellafield plant. Much of the radionuclide inventory is present in the soil and leaf litter [6].

The second site is an ungrazed mature salt marsh within the Esk Estuary, Cumbria, which receives low-level radionuclide input from tidal inundation on a daily basis. Like Lady Wood, the site has 
remained undisturbed for over 40 years. The study area was established along the grassland margin of the salt marsh, because the wildlife species under investigation were thought unlikely to traverse and feed within the marsh area. Vegetation cover is dominated by red fescue (Festuca rubra), and soft brome (Bromus mollis).

The sand dune site lies close to the point where the low-level radioactive liquid waste discharge pipeline from Sellafield enters the sea. The dunes form a corridor up to $50 \mathrm{~m}$ wide, which runs parallel to the coastline, separated from nearby agricultural land by the River Ehen. Based on a predominant onshore wind, the bulk of the radionuclides are thought to derive from the marine environment, reentrained to atmosphere. The frontal mobile dunes are partly stabilised by marram (Ammophila arenaria), whilst the rear slack region is dominated by $F$. rubra.

\section{INDICATOR SPECIES}

Five indicator species were selected, covering different trophic levels: the granivorous wood mouse (Apodemus sylvaticus), the herbivorous field vole (Microtus agrestis), the insectivorous common shrew (Sorex araneus), the predatory violet ground beetle (Carabus violaceous) and the detritivorous wood louse (Oniscus asellus). These species have small home range sizes suggesting that contaminated soil and food items from the study areas will be the main source of radionuclide uptake and exposure.

\section{DOSE CALCULATIONS}

Doses to organisms were determined in three parts, i) internal from alpha, beta and gamma emissions, ii) external beta, and iii) external gamma. It has been assumed that alpha emissions do not contribute significantly to the external dose received. Dosimetric models adopted in this study have been described in detail elsewhere [7] and are summarised here.

\subsection{Internal Dose Calculation}

Activity concentrations for ${ }^{134} \mathrm{Cs},{ }^{137} \mathrm{Cs},{ }^{238} \mathrm{Pu},{ }^{239+240} \mathrm{Pu}$ and ${ }^{241} \mathrm{Am}$ within each indicator species were measured and the internal dose rates were estimated using the approach of the US National Council for Radiation Protection and Measurements [8]:

$$
H_{\mathrm{int}}=\sum_{i, j} C_{i} \times P_{i, j} \times E_{i, j} \times f_{i, j} \times 5.06 \times 10^{-9}
$$

$H_{\text {int }}=$ internal absorbed dose $\left(\mathrm{Gy} \mathrm{a}^{-1}\right)$

$C_{i}=$ activity concentration of radionuclide $i$ in target organism (Bq kg-1)

$P_{i, j}=$ fractional emission yield of photon or particle $j$ from nuclide $i$

$E_{i, j}=$ energy of photon or particle $i$ from nuclide $j(\mathrm{keV})$

$f_{i, j}=$ fraction of particle or photon energy absorbed within the organism

This method assumes a uniform distribution of the radionuclide of interest in the target organism. The absorbed fractions for gamma ray and beta particle energies were determined from the tabulations provided by NCRP [8]. An absorbed fraction of unity was assumed for all alpha particle energies.

\subsection{External Beta Dose Calculation}

For beta particles, with a relatively short penetration range in most media, an infinite or semi-infinite source approach is appropriate [9], particularly for organisms with dimensions less than about $10 \mathrm{~mm}$, where:

$$
\begin{aligned}
& H_{e x t}^{\text {inf }}=5.06 \times 10^{-9} \times C_{i}^{\text {med }} \sum_{i, j}\left(1-f_{i, j}\right) P_{i, j} E_{i, j} \\
& H_{e x t}^{\text {semi }}=2.53 \times 10^{-9} \times C_{i}^{\text {med }} \sum_{i, j}\left(1-f_{i, j}\right) P_{i, j} E_{i, j}
\end{aligned}
$$

$H_{\text {ext }}=$ external dose $\left(\mathrm{Gy} \mathrm{a}^{-1}\right)$

$C_{i}=\quad$ activity concentration of radionuclide $i$ in soil $\left(\mathrm{Bq} \mathrm{kg}^{-1}\right)$

$P_{i, j}=$ fractional emission yield of particle or photon $j$ from radionuclide $i$

$E_{i, j}=$ energy of particle or photon $j$ from radionuclide $i(\mathrm{keV})$

$f_{i, j}=$ fraction of energy from particle or photon $j$ from nuclide $i$ absorbed [from 8] 
The infinite medium approximation ( $H^{i n f}$, equation 2 ) is used for burrowing organism and the semiinfinite medium approximation $\left(H^{\text {semi }}\right.$, equation 3 ) is used for organisms on the surface.

\subsection{External Gamma Dose Calculation}

External dose is calculated as:

$$
H_{e x t}=C, x D C F\left(G y a^{-1}\right)
$$

$H_{e x t}=\operatorname{external~dose~}\left(\mathrm{Gya}^{-1}\right)$

$C_{t}=$ activity concentration of radionuclide $i$ at time t per core slice $\left(\mathrm{Bq} \mathrm{m}^{-2}\right)$

$D C F=$ Dose conversion factor

The dose conversion factors take into account shielding due to the depth of soil between the target organism and the layer of radioactivity in the soil profile [10].

The model is run twice: first assuming that the target species is on the soil surface and, second, with the organism at a burrowing depth appropriate to the ecology of the species. The results are then multiplied by the fraction of day spent at each position.

\section{ESTIMATES OF ABSORBED DOSE}

The depth profile of ${ }^{137} \mathrm{Cs}$ in soil from the three sites is presented in Table 1. Lady Wood exhibits a classic profile with maximum concentrations near the surface; the River Esk profile shows a sub-surface maxima; and the sand dunes exhibit an increasing concentration with depth, reflecting leaching through the coarse sand particles.

Table 1: Average ${ }^{137} \mathrm{Cs}$ Activity concentrations (Bq kg${ }^{-1} \pm$ standard error) in soil profiles from the three field sites

\begin{tabular}{lcrcc}
\hline Depth (cm) & Coniferous Wood & \multicolumn{2}{c}{ Salt Marsh } & Sand Dune \\
\hline $0-4$ & $1,430 \pm 45$ & $11,145 \pm 290$ & $260 \pm 9$ \\
$4-8$ & $660 \pm 21$ & $16,750 \pm 480$ & $280 \pm 13$ \\
$8-12$ & $220 \pm 7$ & $5,270 \pm 160$ & $450 \pm 18$ \\
\hline
\end{tabular}

Table 2 presents the results of the dose calculations for each site. It is evident that, when the radionuclide distribution in the soil core profile is taken into account, the external dose rate is reduced for small mammals compared to invertebrates, at the Lady Wood and salt marsh sites due predominantly to soil shielding, as these burrow into deeper layers. The reverse effect is observed on the sand dunes, where the radionuclide concentration increases with depth. For comparison measured air kerma at each site is also presented.

Table 2: Doses $\left(\mathrm{mGy} \mathrm{d}^{-1}\right)$ to indicator species at three field sites in the vicinity of the BNFL Sellafield nuclear fuel reprocessing plant, Cumbria, UK

\begin{tabular}{|c|c|c|c|c|}
\hline & \multirow{2}{*}{$\begin{array}{l}\text { Measured } \\
\text { air kerma* }\end{array}$} & \multicolumn{2}{|c|}{ Calculated dose to organisms } & \multirow[t]{2}{*}{ Total } \\
\hline & & External & Internal & \\
\hline Woodland & & & & \\
\hline Invertebrate detritivores & $1.7 \mathrm{E}-03$ & $1.86 \mathrm{E}-03$ & $9.08 \mathrm{E}-04$ & $2.77 \mathrm{E}-03$ \\
\hline Invertebrate predators & & $1.86 \mathrm{E}-03$ & $1.33 \mathrm{E}-04$ & $1.99 \mathrm{E}-03$ \\
\hline Apodemus sylvaticus & $2.6 \mathrm{E}-03$ & $9.40 \mathrm{E}-04$ & $8.56 \mathrm{E}-05$ & $1.03 \mathrm{E}-03$ \\
\hline \multicolumn{5}{|l|}{ Salt marsh } \\
\hline Invertebrate detritivores & & $1.77 \mathrm{E}-03$ & $1.05 \mathrm{E}-02$ & $1.23 \mathrm{E}-02$ \\
\hline Invertebrate predators & $1.9 \mathrm{E}-03$ & 4.09E-04 & $1.05 \mathrm{E}-02$ & $1.09 \mathrm{E}-02$ \\
\hline Apodemus sylvaticus & to & $3.34 \mathrm{E}-05$ & $5.08 \mathrm{E}-03$ & $5.12 \mathrm{E}-03$ \\
\hline Microtus agrestis & $7.0 \mathrm{E}-03$ & $6.23 \mathrm{E}-08$ & $5.08 \mathrm{E}-03$ & $5.09 \mathrm{E}-03$ \\
\hline Sorex araneus & & $9.51 \mathrm{E}-08$ & $5.08 \mathrm{E}-03$ & $5.09 \mathrm{E}-03$ \\
\hline \multicolumn{5}{|l|}{ Sand dunes } \\
\hline Invertebrate detritivores & & $1.90 \mathrm{E}-03$ & $1.34 \mathrm{E}-03$ & $3.25 \mathrm{E}-03$ \\
\hline Invertebrate predators & $1.9 \mathrm{E}-03$ & $7.81 \mathrm{E}-04$ & $1.34 \mathrm{E}-03$ & $2.12 \mathrm{E}-03$ \\
\hline Apodemus sylvaticus & to & $4.88 \mathrm{E}-05$ & $2.36 \mathrm{E}-03$ & $2.42 \mathrm{E}-03$ \\
\hline Microtus agrestis & $2.4 \mathrm{E}-03$ & $2.54 \mathrm{E}-06$ & $2.36 \mathrm{E}-03$ & $2.37 \mathrm{E}-03$ \\
\hline Sorex araneus & & $1.20 \mathrm{E}-05$ & $2.36 \mathrm{E}-03$ & $2.37 \mathrm{E}-03$ \\
\hline
\end{tabular}

"Expressed nett of background; assumed to be $0.04 \mu \mathrm{Gy} \mathrm{h}^{-1}$ at Ladywood, $0.05 \mu \mathrm{Gy} \mathrm{h}^{-1}$ at the coastal sites. 
The external beta dose is higher in the small mammals relative to the invertebrates, as their greater body size is more effective at absorbing these particles. Internal beta/gamma dose rates are also affected by the size of the species. The beta dose component is higher due to its short penetration range and consequent higher effective absorption.

The internal alpha dose component is variable. Generally this constitutes a low dose contribution for the mammal species, reflecting the low gastro-intestinal transfer rates. At the River Esk site the activity concentrations in the sediment for ${ }^{238} \mathrm{Pu},{ }^{239+240} \mathrm{Pu}$ and ${ }^{241} \mathrm{Am}$ range between 100-700, 950-3250 and 400$8800 \mathrm{~Bq} \mathrm{~kg}{ }^{-1}$ respectively, but it is suggested that the high affinity of fine sediment particles for actinides makes them effectively unavailable for transfer through the food chain. By contrast, the dose from the actinides to the invertebrate species listed is up to 5 orders of magnitude greater.

\section{DISCUSSION}

\subsection{Approaches to ecological risk assessment}

All aspects of Ecological Risk Assessments, from basic concepts to methodologies and implementation in the field, are currently being debated. One approach involves quantifying the effect of a stressor on individual receptor organisms, populations or species, which may be selected on the basis of different characteristics. These include: 1) those likely to be exposed to the highest levels of radiation; 2) those likely to be the most sensitive species; 3 ) those of ecological importance in the transfer of energy through trophic levels (e.g. primary producers or detritivores); 4) those identified as species considered valuable by society (such as rare or endangered species, or those protected by law); or 5) species ubiquitous to many regions (providing a common reference framework). Considering organisms likely to be exposed to the highest levels has similarities with the 'critical group' approach adopted for the protection of man. Inherently, however, such an approach assumes that protection of one species, on the basis of exposure patterns alone, will result in protection of all species. In this context, protecting the most sensitive species may afford a more defensible approach. However, a primary limitation on this approach is the identification of suitable indicator species. Indeed this criticism could be applied for any approach which relies on identifying the one individual, population or species which represents the most extreme case (for any characteristic) from within a complex, diverse, ecosystem.

Consequently an alternative approach has been promulgated for discussion, from the opposite end of the spectrum, which examines the effects of stressors on the structure and functioning of entire ecosystems. Although superficially attractive (particularly where we are more concerned with broader environmental effects such as biodiversity), there are deficiencies in our understanding of the ecological interactions of contaminants and the role particular species play in the structure and functioning of ecosystem or ecological succession [11].

Another approach focuses on the designation of reference dosimetric models. Although there remains a requirement to identify a number of common species upon which such a model could be developed (e.g. for different body sizes or trophic levels), the reference model approach has a number of potential advantages. Not least, such an approach would permit the development of a standardised series of criteria suitable for broad application based on a relatively few environmental monitoring measurements, and thus offer some degree of compatibility with current environmental monitoring regimes.

\subsection{Setting dose threshold values}

Whichever approach is taken to assess impact, there remains a need to demonstrate adequate protection. It is therefore suggested that identifying critical or most sensitive species in any given scenario wil remain essential and a relationship needs to be established with the reference model. It has been suggested, tentatively, that chronic exposure of terrestrial organisms below about $1 \mathrm{mGy} \mathrm{d}^{-1}$ will not result in measurable detrimental effects on populations of terrestrial organisms, even for sensitive species [12]. It is clear from Table 2 that the selected species inhabiting each field site receive doses between $2 \cdot 3$ orders of magnitude lower than this level. There are, however, criticisms that can be levelled at the $\mathrm{mGy} \mathrm{d}^{-1}$ value and its application. First, the value is only a guideline with little direct evidence to support its application. In this sense, it may not be a much better measure for environmental protection than the generic statements of the ICRP. Moreover, a number of recent studies have shown scorable cytogenetic effects occurring at dose rates well below $1 \mathrm{mGy} \mathrm{d}^{-1}$ [9]. The relevance of these effects to the long-term health of individuals and populations has not yet been established; but more work on sub-lethal effects is required, including the assessment of changes in sensitivity over life cycles from neonate to adult and with particular consideration of metamorphic or instar stages. 
Field studies by Chesser et al. [13] around Chernobyl have indicated that population densities of mammals in the $10 \mathrm{~km}$ exclusion zone, where external dose rates substantially in excess of $10 \mathrm{mGy} \mathrm{d}^{-1}$ may be experienced in some areas, are actually higher than in nearby, low radiation, habitats. In an experimental exposure of naïve bank voles in a high radiation site in the exclusion zone, averaging $30^{+}$ $\mathrm{mGy} \mathrm{d}^{-1}$, Rodgers et al. [14] found no evidence of reproductive inhibition. Furthermore, there was no evidence of significant genetic damage as assessed by micronucleus assay. The annual dose to organisms in this area would exceed $1 \mathrm{~Gy}$, which equates to the postulated acute lethal dose for $50 \%$ of the population within 30 days $\left(\mathrm{LD}_{50 / 30}\right)$. Whilst it is known that chronic exposure does not show simple cumulative effects, these results suggest that the determination of effective threshold limits requires further consideration.

\subsection{Methods for determining dose}

Comparison between measured air kerma and estimated external doses to organisms at all three field sites in this study indicate reasonable agreement. This gives some reassurance that the method used to determine external dose provides a reasonable approach. Moreover, since this fraction appears to dominate total dose, there is an indication that the low calculated dose to each species reflects conditions in the field.

At the same time, one identifiable flaw in the dose calculation methodology described is the lack of assessment of organ doses within the indicator species. It is known that organs and tissues in humans respond differently to radiation exposure but no account of this is taken here. In addition, no account is taken of the relative biological effectiveness (RBE) of different types of radiation. Applying an RBE of 20 for alpha radiation may not be unreasonable for the mammalian species, as it was originally deternined for man from experiments on a wide range of organisms [7]. It is more questionable to apply this factor to invertebrates and there is a requirement to determine appropriate radiation weighting factors for these species. A new system of scientific units, equivalent to the sievert, may need to be derived on a species or taxa specific basis.

\subsection{Use of biomarker techniques}

Multiple biomarker techniques may be used to quantify the biological impact of exposure to environmental contaminants, both radioactive and non-radioactive. Preliminary work underway suggests this approach may inform discussions on environmental protection by:

- providing an indication of the overall effect of exposure to whatever environmental contaminants are present and from whichever uptake or transfer pathway;

- being independent of estimates of bioavailability of contaminants;

- indicating the effects of exposure to mixtures of contaminants (e.g. synergistic or antagonistic effects);

- identifying capacities for detoxification and repair.

It is recognised however that the relationship between the biomarker measurement and the ecological response of the target organism needs to be understood before these techniques can become widely accepted.

\section{CONCLUSIONS}

The absorbed dose rates (without correction for RBE) described for wildlife species in the three seminatural ecosystems around BNFL Sellafield are low. When compared to a $1 \mathrm{mGy} \mathrm{d}^{-1}$ threshold value currently being discussed, the risk of harm to these species is also believed to be low. However, there are questions raised by this approach to dose estimation, not least the discrepancy in our ability to estimate doses to non-human species without the appropriate well-defined numerical relationship between the quantity describing the radiation exposure and its biological effects. It is therefore advocated that a tevised approach to dosimetric assessment be considered by linking the current dose assessment methodology with the use of a new system for assessment using techniques which can quantify levels of biological damage induced within biota by both radioactive and non-radioactive contaminants in the environment. This has the significant advantage that the stress induced by different environmental contaminants is considered as a whole, instead of the piecemeal approach currently used.

In addition, the establishment of an appropriate dose threshold requires further consideration. Available evidence suggests that scorable cytogenetic effects may occur below $1 \mathrm{mGy} \mathrm{d}^{-1}$ in a number of 
species, but studies on small mammal populations around Chernobyl indicate that doses in excess of 30 $\mathrm{mGy} \mathrm{d}^{-1}$ have no discernible cytogenetic or reproductive impact.

\section{Acknowledgements}

The authors gratefully acknowledge the financial support of British Nuclear Fuels plc. They also thank John Prescott for his assistance with the radiochemical separations and Dr Mark Willans (WSC) for providing the Fortran code to run the Kocher and Sjoreen external dose calculations. Any opinions stated in this paper are those of the authors alone and do not represent the policy adopted or endorsed by BNFL.

\section{References}

[1] ICRP. Recommendations of the International Commission on Radiological Protection, Ann ICRP 60 1-201 (1991).

[2] Pentreath $\mathrm{J} A$ system for radiological protection of the environment: some initial thoughts and idens J Radiol Prot 19 117-128

[3] Thompson PM Environmental monitoring for radionuclides in marine ecosystems; are species other than man protected adequately? J Environ. Radioactivity $7275-283$ (1988).

[4] Linsley $G$ Protection of the natural environment and internationally accepted practice. Proceedings of the First International Symposium on Ionising Radiation, Stockholm, May 20-24 1996. 27.35 (1996).

[5] Santillo D, Stringer RL, Johnston PA and Tickner J The precautionary principle: protecting aguinst failures of scientific method and risk assessment, Mar. Pollut. Bull. 3612 939-950 (1998).

[6] Copplestone D, Johnson MS and Jones SR Radionuclide behaviour and transport in a coniferons. woodland ecosystem: the distribution of radionuclides in soil and leaf litter, Water Air Soil Pollut.122 389-404 (2000).

[7] Copplestone D, Toal ME, Johnson MS, Jackson D and Jones SR (2000) Environmental effects of radionuclides - observations on natural ecosystems, J. Radiol. Prot. 20 29-40.

[8] NCRP. Effects of ionizing radiation on aquatic organisms. Report No 109 (1991).

[9] Sokolov VE and Krivolutsky DA Change in Ecology and Biodiversity after a Nuclear Disaster in the Southern Urals. Pensoft Publishers (1998).

[10] Kocher DC and Sjoreen AL Dose-rate conversion factors for external exposure to photon emitters in soil, Health Phys. 482 193-205 (1985).

[11] Power M and McCarty LS Fallacies in Ecological Risk Assessment Practices, Environ. Sci. Technol. 318 370-375 (1997).

[12] IAEA. Effects of Ionizing Radiation on Plants and Animals at Levels Implied by Current Radiation Protection Standards. Technical Reports Series No 332 (1992).

[13] Chesser RK, Sugg DW, Lomakin, MD, van den Bussche RA et al. Concentrations and dose rate estimates of 134,137 cesium and 90 strontium in small mammals at Chornobyl, Ukraine, Environ. Toxicol. Chem. $19305-312$ (2000)

[14] Rodgers BE, Wickliffe JK, Phillips CJ, Chesser RK and Baker RJ Experimental exposure of naive bank voles (Clethrionomys glareolus) to the Chornobyl environment: a test of radioresistance Environ. Toxicol. Chem. $20(2000)$ 